\title{
Perspectives
}

\section{The Myth of FANBOYS: Coordination, Commas, and College Composition Classes}

Brett Reynolds

The claim that the words for, and, nor, but, or, yet, and so (FANBOYS) constitute a complete list of English coordinating conjunctions is examined though syntactic analysis and found wanting. This analysis is presented as an illustration of the need for teachers constantly to question the choice of material that we present to our students and our reasons for presenting it.

En Anglais, on prétend que les mots for, and, nor, but, or, yet et so, qui forment la mnémotechnique FANBOYS, constituent la liste complète des conjonctions de coordination en anglais. Notre analyse syntaxique a révélé que ce n'était pas le cas. Nous la présentons afin d'illustrer l'importance pour nous les enseignants de constamment remettre en question le choix de matière que nous présentons à nos élèves et les raisons qui nous poussent à la présenter.

The first time I walked into the college writing center, FANBOYS was pasted in large letters across one wall. What in the world were FANBOYS? The writing center coordinator characterized the thinking behind the FANBOYS mnemonic for me as follows: "A comma and a coordinating conjunction (for, and, nor, but, or, yet, and so exclusively) work together as a meaningful semicolon: they join independent clauses that retain their independence once so joined. Subordinate conjunctions like because introduce dependent clauses that stay dependent. The structural distinction is an important one as it impacts among other things on punctuation" (Franc Jamieson, personal communication, May 17, 2005). ${ }^{1}$

Although I did not know it at the time, this view is echoed in scores of college composition textbooks on writing (Folse, Muchmore-Vokoun, \& Vestri Solomon, 2004; Kennedy-Isern, 2001; Werier, Scarry, \& Scarry, 2002). Rarely, though, do these textbooks provide argumentation or cite any linguistic studies to support the claim. It is merely taken as an axiom. Zwicky (2006) could be talking about exactly this point when he writes that it

is no more than recitation of a piece of a catechism, reproduced without understanding; a reader who takes it to be a claim about English and tries to test it will quickly come upon (counter)examples ... and conclude that the claim is false, while everyone else will just memorize it as a definition and pass on, no wiser. 
This is the issue that I address here: the credulity with which linguistic claims are so often accepted or even embraced and the lack of any educational value behind how they are taught. I begin by arguing that FANBOYS as articulated above is a myth. Myths are fictions created to deal simply with a difficult and confusing world. They are shared by members of a certain community and to a certain extent identify that community. Myths can take on great import among the community of believers. Finally, they can serve a gatekeeping function, preserving power for those who know or "understand" the myths and denying those who do not. I think FANBOYS qualifies as a myth under each of these characteristics, and I use this myth as a parable to nudge our thinking about various other linguistic prescriptions and descriptions (Nunberg, 1997).

\section{The History of FANBOYS}

Teachers of grammar and writing often rely heavily on traditional analyses, and it may be the case that FANBOYS has gained credibility through a long and venerable history. Then again, maybe not. The earliest attestation I have found of the FANBOY (sans S) mnemonic is a 1951 book called Learning to Write (Smith, Paxton, \& Meserve, 1951), and the wording there suggests that it was already widely used, whereas according to Hagen (2009), the first full FANBOYS attestation appears in a 1970 book entitled Language Arts in the Elementary School: A Modern Linguistic Approach.

There are, however, many lists. Barron's 1001 Pitfalls in English Grammar (Hopper \& Craig, 1986) asserts, "the coordinating conjunctions are: and, but, or, nor, for, whereas, yet, so" (p. 6) (FANBOWYS). Brown (1953) claims, "The co-ordinating conjunctions are and, or, for, but and nor ... Then, yet, so, thus, therefore, consequently, moreover, however and nevertheless are some common co-ordinating conjunctive adverbs" (pp. 182-183) (FANBO). The Elements of Style (Strunk, 1935) instructs us to place a comma before a conjunction introducing an independent clause. It then gives two examples-one with and and one with but-before continuing with the following prescript: "Two-part sentences of which the second member is introduced by as (in the sense of because), for, or, nor, and while (in the sense of and at the same time) likewise require a comma before the conjunction" (p. 4) (FANBOWA). Reed and Kel$\operatorname{logg}$ (1896) list and, as well as, but, whereas, neither, nor, and or (ANBOWNA). The most permissive list comes from An English Grammar: For the Use of High School, Academy, and College Classes (Baskerville \& Sewell, 1895):

297. Coördinate [sic] conjunctions are of four kinds:

(1) COPULATIVE, coupling or uniting words and expressions in the same line of thought; as and, also, as well as, moreover, etc.

(2) ADVERSATIVE, connecting words and expressions that are opposite in thought; as but, yet, still, however, while, only, etc. 
(3) CAUSAL, introducing a reason or cause. The chief ones are, for, therefore, hence, then.

(4) ALTERNATIVE, expressing a choice, usually between two things. They are or, either, else, nor, neither, whether." (WHETSTONE WHAM BOY FAN) (p. 194)

Clearly, then, no historical consensus supports FANBOYS as the only "coordinating conjunctions." So which version is right? Which do I teach my students? We need to apply some syntactic analysis to discover the answers.

\section{Lack of Coherence in FANBOYS}

Perhaps the place to start is with the three words that seem to be common to all lists: and, or, but. These three are also considered prototypical ${ }^{2}$ coordinators by most modern comprehensive grammars including The Oxford English Grammar (Greenbaum, 1996), The Cambridge Grammar of the English Language (Huddleston \& Pullum, 2002), and The Longman Grammar of Spoken and Written English (Biber, Johansson, Leech, Conrad, \& Finegan, 1999). ${ }^{3}$ These three words share a number of properties. In particular, they (a) cannot occur contiguously; (b) are not subject to modification; (c) can conjoin constituents of all sizes from word, to phrase, to clause; and (d) link coordinates that are typically commutative.

It is worthwhile to consider which of these properties apply to for, yet, and so. The first property to examine is the inability of coordinators to appear contiguously. Here yet and so differ from core coordinators in that they can be paired with them. Consider the examples in 1.

1. a. *He went along, and but he felt uncertain.

b. He went along, and yet he felt uncertain.

c. He went along, and so he felt uncertain.

A second characteristic is that coordinators do not head phrases of any sort, which means that they cannot be modified. A noun phrase (NP), for example, can consist of an isolated noun, but it can also take an attributive modifier as in the NP happy days, where happy modifies days. In this respect, so, which can be modified by just, differs from the core coordinators.

Next, consider the property of being able to coordinate a wide range of constituents such as clauses, verb phrases (VPs), noun phrases, and adjectives. Each FANBOYS word can join clauses, but for, so, and yet are limited to specific clause types. Declarative content clauses, for example, can be conjoined by the core coordinators yet and so, but not for.

2. a. We hope (that) they change the law again so (that) they'll have a chance for freedom (Davies, 2008). ${ }^{4}$

b. "We hope (that) they change the law for (that) they'll have a chance for freedom. 


\section{c. He wished (that) his first marriage had never ended, yet (that) his second had occurred. (Davies, 2008)}

Conjunction of closed interrogative content clauses such as whether they're really interested is similarly not achieved with for, so, and yet. Nor can these words join comparative clauses like than it used to be. Below the clausal level, for conjoins nothing at all, and although yet and so can join VPs and adjective phrases (AdjPs), it is quite rare ${ }^{5}$ for so to do so.

3. a. I found a Target that is easier to get to, so went there by bus last night. (VPs) (Lori, 2008)

b. Both are new so relatively untested. (AdjPs) (PeterBr, 2007)

Of the non-core members, yet is the most flexible, being able to join relative clauses, adverb phrases (AdvPs), and NPs:

4. a. other units that haven't even been identified yet that are engaged in combat in Iraq (Davies, 2008)

b. clad sloppily yet stylishly in a blue checked shirt, khakis and Chuck Taylor All-Stars (Davies, 2008)

c. She gave a name yet not her surname.

The final property that we consider is that of coordinates being commutative. It is often possible to transpose the coordinates without changing the overall meaning. The same often holds for yet, but with so and for commutation is never possible.

5. a. I live in London and I go to Western. $=\underline{\text { I go to Western }}$ and I live in London.

b. I live in London so I go to Western. $\neq$ I go to Western so I live in London.

c. I live in London for I go to Western. $\neq \underline{\text { I go to Western for I live in }}$ London.

Admittedly, other characteristic properties of coordinators are shared by some or all of the words in question (for, yet, and so, as well as other words and phrases, see below). Despite such overlap, so and for share few of the properties and are much more like prepositions with clausal complements (Huddleston, Payne, \& Peterson, 2002). And yet has much more in common with connective adverbs such as however, the main difference being that the position of yet (in the contrastive sense) is fixed clause initially, unlike most adverbs:

6. a.... I, therefore, need to buy some milk.

b. *... I, yet, need to buy some milk.

In short, FANBOYS includes a number of marginal and noncoordinators better analyzed as adverbs or prepositions contrary to the claim that they are all coordinators.

\section{Lack of Exhaustiveness in FANBOYS}

Not only is the status of FANBOYS as a coherent set challenged by lack of homogeneity, it fails too in terms of exhaustiveness. Recall that the claim with regard to FANBOYS is that they exclusively and in conjunction with a comma work as a meaningful semicolon. In fact, other markers can work either in- 
dividually or with a comma to coordinate clauses, although as with for, so, and yet, these are not prototypical members of the coordinator class. Rather than attempt an exhaustive list, I give a number of examples. These are underlined in 7 below. Huddleston et al. (2002) state that these are all well established in English grammar, but college writing teachers may object to some on stylistic grounds.

7. a. Not only was she late, she was also unprepared.

b. She means what she says as well as says what she means.

c. He was lazy plus he smoked.

d. I had hoped to see her, only she wasn't home.

e. First select file then click $O K$.

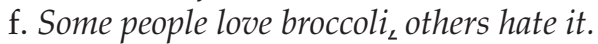

Thus contrary to the claims, FANBOYS are neither homogeneous nor exhaustive, and as such do not form a logical set.

\section{The Comma Requirement}

A second problem with the myth is the claim that "a comma and a co-ordinating conjunction ... join independent clauses." In practice, this often means that students are told that they must use a comma with FANBOYS, and some teachers deduct marks for missing commas. I suppose it could be justified as a stylistic deviation, but several heavy punctuation styles use such commas regularly, and some lighter styles do not (Nunberg, Briscoe, \& Huddleston, 2002). Meyer (1987), in a statistical study of a sub-corpus of the Brown corpus, found that the use of commas varied significantly in clausal coordination. In particular, he found that whereas $87 \%$ of the instances of and in such situations were preceded by a comma, the incidence was only $64 \%$ for or $^{6}$

In a cursory examination of college textbooks, I found numerous instances of clausal coordination with a coordinator, but no comma. A few examples are listed in 8.

8. a. To wash a person's back if they cannot sit forward, and to wash people's buttocks, you need to turn them on their side and you may require assistance to do this. (DeLaune \& Ladner, 2002, p. 115)

b. There was little turnover in band personnel and players had more time to rehearse. (Martin \& Waters, 2005, p. 10)

c. Field hollers were both a form of song and a means of communication; in half-sung, half-shouted language, the worker called for water or asked for help across large distances in the cotton fields. ${ }^{7}$ (p. 14)

d. Was it an American culture that emphasizes health concerns? Or was it an equally American anxiety about litigation? (Ebert, Griffin, \& Starke, 2002, p. 60)

e. Except for a few collections of transcriptions, the only tangible sources of information are diaries, letters, newspapers, and novels, as well as paintings and pictures - but these do not always depict African-American music clearly or reliably. (Martin \& Waters, p. 18) 
When I asked a number of college teachers, not ESL or writing teachers, to comment on the grammaticality of the sentences in 7 and 8 , none mentioned a need for a comma before the coordinator. ${ }^{8}$

Of course, many people favor these commas, and as Bayparktar, Say, and Akman (1998) write, "independent clauses joined by a coordinating conjunction, such as and, or, but, etc., may be separated by a comma, if there is a risk of misreading" (p. 36). ${ }^{9}$ Yet there are instances of clausal coordination where a comma simply gets in the way, especially with relatively short coordinates, as in 9 .

9. a. Hurry, or we'll miss it.

b. I came, and he left.

\section{Discussion}

This leads to the question: What does teaching FANBOYS accomplish? Given the confusion among teachers between coordination and subordination, how can we expect students to tell the difference, and is it even relevant? How are students who have bought into the myth likely to deal with words such as although? Will they conclude that such words should not be preceded by a comma? Most importantly, if students are acculturated into the myth, will they be better writers? Will their other teachers or future employers notice a difference?

Where did this myth come from? Most probably, some influential author suggested that meaning might be clarified by the insertion of a comma before FANBOYS. Later, perhaps this was misremembered as a rule rather than as a rule of thumb. Alternatively, maybe the original formulation was closer to: Where a dependent clause is followed by a coordinator and a clause that could be either dependent or independent, a comma before the coordinator signals that the second clause is independent. ${ }^{10}$ This very limited observation might then have been overgeneralized. Yet how one arrives at FANBOYS as a list of coordinators is difficult to imagine.

Whatever its origin, the myth seems to have become part of teacher lore and been propagated through other use and writing books, their authors copying slavishly from those who came before. The reason for its staying power, though, is clear: like any good myth, it gives the faithful a comfortingly simple handhold in a confusing world-in this case, that of composition. To paraphrase Knoblauch and Brannon (1984), it is extremely hard to teach students to be good writers; it is much easier to teach them the myth of FANBOYS.

I have found that many writing teachers, despite years of tertiary and postgraduate education, were unaware of the myth of FANBOYS until they began teaching college composition. Some have told me that this led to a certain amount of anxiety; how could they have missed this rule? But as they became acculturated into the college composition teaching culture, a few internalized the myth and now believe it to be both true and important for their students to learn. 


\section{Conclusion}

Thus FANBOYS has taken on a mythical status far beyond its utility or basis in reality. College composition teachers are the intelligentsia (or priesthood) who know and control the myth, who propagate it to maintain the stability of the culture in which we have achieved a position of relative power, and who use it to impose conformity on the uninformed student laity.

However, it is not simply a matter of FANBOYS being used as a marker of acculturation that should trouble us. It is the lack of any real learning connected to "rules" of this sort. They are mere injunctions, exhortations-do! But more often don't!

Really? Why? How? These are questions too rarely pondered in such situations. But what if we brought to bear the tools of grammatical analysis, asking, What would happen if we were to move constituents around, to substitute another word, to put the clause in the passive voice, or to subordinate the whole thing? What could we learn by searching for published instances of the construction in question, by looking at frequencies and genres? What indeed? Perhaps by wondering, observing, and experimenting, perhaps then we could take these issues not as shibboleths to deny entrance to the unwashed, but as entrances that open onto possibilities of investigation, not as dogma to be swallowed whole, but as parables to be prodded and poked and considered as we struggle to find just the right way to compose our thoughts.

\footnotetext{
Notes

${ }^{1}$ This is not to imply that this is Jamieson's own understanding of coordination.

2 "While central or prototypical cases of coordination and subordination are distinct, there is no clear boundary between the peripheries of the constructions" (Huddleston, Payne, \& Peterson, 2002, p. 1289).

${ }^{3}$ All three grammars also view nor as a coordinator, but treat it somewhat differently given the syntactic changes it imposes on a sentence (subject-verb reversal) and its strong tendency to appear with neither.

${ }^{4}$ The grammatical examples that follow have been extracted from the cited sources. The ungrammatical examples and parenthetical insertions are modifications thereof. Uncited examples are my own constructions.

${ }^{5}$ I could find no examples in the 425+-million-word Corpus of Current American English (Davies, 2008).

${ }^{6}$ This includes commas marking parenthetical insertions before the conjunction (e.g., He got up, having heard the news, and went to the phone).

${ }^{7}$ In the admittedly small corpus that was examined, no instances of or, with or without a comma, were found in which the subject was explicitly stated in the second clause. This raises the question of whether teaching the myth of FANBOYS promotes unnatural redundant inclusion of subjects in the second clause.

${ }^{8}$ They were, however, merciless in their condemnation. No sentence was entirely spared as adjectives such as awkward, ambiguous, and incoherent flew. Moral: if you ask somebody if something is wrong with a sentence, expect them to find something.
} 
${ }^{9}$ In fact, as Truss (2004) observes of commas, "When it comes to improving the clarity of a sentence, you can nearly always argue that one should go in; you can nearly always argue that one should come out" (p. 80).

${ }^{10}$ Consider the change in meaning caused by the insertion of a comma before and in Karla Homolka's post-prison statement during a Radio-Canada interview, "I don't want people to think I am dangerous and I'm going to do something to their children" (CTV News, July 5, 2005).

\section{Acknowledgments}

I thank the following people for feedback on the article: Geoff Pullum, Franc Jamieson, Karen Golets Pancer, and Michael Reynolds. Any errors remaining are my own. Earlier versions of this article were presented at the 2007 TESL Ontario Conference, Toronto, and at the 2007 College Association for Language and Literacy Conference, Toronto.

\section{The Author}

Brett Reynolds is a professor of EAP in the English Language Centre at Humber College Institute of Technology and Advanced Learning, Toronto.

\section{References}

Baskerville, W.M., \& Sewell, J.W. (1895). An English grammar: For the use of high school, academy, and college classes. New York: American Book Company.

Bayraktar, M., Say, B., \& Akman, V. (1998). An analysis of English punctuation: The Special case of comma. International Journal of Corpus Linguistics, 3, 33-57.

Biber, D., Johansson, S., Leech, G., Conrad, S., \& Finegan, E. (1999). Longman grammar of spoken and written English. Harlow, UK: Pearson Educational.

CTV News Staff. (2005, July 5). Homolka says: "I still haven't forgiven myself." Available: http:/ / www.ctv.ca/generic/WebSpecials/homolka/index.html

Davies, M. (2008). The corpus of contemporary American English (COCA): 425+ million words, 1990-2011. Available: http:/ /www.americancorpus.org

DeLaune, S.C., \& Ladner, P.K. (2002). Fundamentals of nursing: Standards and practice. Albany, NY: Thomson Delmar Learning.

Ebert, R.J., Griffin, R.W., \& Starke, F.A. (2003). Business essentials (3rd ed.). Toronto, ON: Pearson.

Folse, K.S., Muchmore-Vokoun, A., \& Vestri Solomon, E. (2004). Great paragraphs (2nd ed.). Boston, MA: Houghton Mifflin.

Greenbaum, S. (1996). The Oxford English grammar. Oxford, UK: Oxford University Press.

Hagen, K. (2009). Comma fanboys. Pollysyllabic. Available: http://www.polysyllabic.com/?q=node/244

Hopper, V.F., \& Craig, R.P. (1986). Barron's 1001 pitfalls in English grammar. Hauppauge, NY: Barron's Educational Series.

Huddleston, R.. Payne, J., \& Peterson, P. (2002). Coordination and supplementation. In R. Huddleston \& G.K. Pullum (Eds.), The Cambridge grammar of the English language (pp. 1273-1362). Cambridge, UK: Cambridge University Press.

Huddleston, R., \& Pullum, G.K. (2002). The Cambridge grammar of the English language. Cambridge, UK: Cambridge University Press.

Kennedy-Isern, K. (2001). The write path: Basics of paragraph writing. Boston, MA: Heinle.

Knoblauch, C.H., \& Brannon, L. (1984). Rhetorical traditions and the teaching of writing. Upper Montclair, NJ: Boynton/Cook.

Lori. (2008, July 29). Ups and downs [Web log message]. Available:

http:/ / bysongasaurus.wordpress.com/2008/07/29/ups-and-downs/

Martin, H., \& Waters, K. (2005). Jazz: The first 100 years. Boston, MA: Schirmer. 
Meyer, C.F. (1987). A linguistic study of American punctuation. New York: Peter Lang.

Nunberg, G. (1997, March). The decline of grammar. Atlantic Online. Available: http://www.theatlantic.com/past/docs/issues/97mar/halpern/nunberg.htm

Nunberg, G., Briscoe, T., \& Huddleston, R. (2002). Punctuation. In R. Huddleston \& G.K. Pullum, The Cambridge grammar of the English language (pp. 1723-1764). Cambridge, UK: Cambridge University Press.

PeterBr. (2007, March 17). NordkappLV/Aquanaut LV [Web log message]. Available: http:/ / www.paddling.net/message / showThread.html?fid=advice\&tid=628928

Reed, A., \& Kellogg, B. (1896). Graded lessons in English: An elementary English grammar, consisting of one hundred practical lessons, carefully graded and adapted to the class-room. New York: Clark \& Maynard.

Smith, R., Paxton, B., \& Meserve, B. G. (1951). Learning to write (3rd ed.). Boston, MA: Heath. Available: http:/ / books.google.ca/books?id=v50FAQAAIAAJ

Strunk, W.J. (2005). The elements of style. Mineola, NY: Dover Publications.

Truss, L. (2004). Eats, shoots, and leaves: The zero tolerance approach to punctuation. New York: Gotham Books.

Werier, C., Scarry, S., \& Scarry, J. (2002). The sentence to paragraph: Workplace. Scarborough, ON: Nelson.

Wong, L. (2002). Paragraph essentials. Boston, MA: Houghton Mifflin.

Zwicky, A. (2006, December 28). Two ways to look at the passive. Language Log. Available: http://itre.cis.upenn.edu/ myl/languagelog/archives/003984.html 